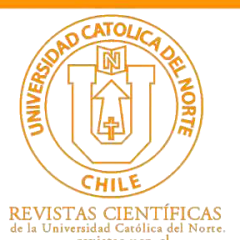

\title{
Irregularity indices for line graph of Dutch windmill graph
}

Mohanad A. Mohammed ${ }^{1}$ (D) orcid.org/0000-0002-7507-1212

Suad Younus A. AL-Mayyahi ${ }^{2}$

Abaid ur Rehman Virk ${ }^{3}$ (D) orcid.org/0000-0001-7312-9225

Hafiz Mutee ur Rehman ${ }^{4}$ (1) orcid.org/0000-0002-7496-5804

${ }^{1}$ Open Educational College, Dept. of Mathematics, Al Qadisiya Centre, Ministry of Education,Amarah, Iraq

mohanadalim@gmail.com

${ }^{2}$ University of Wasit, Dept. of Mathematics, Faculty of Education for Pure Sciences, Wasit, Kut, Iraq

$\square$ isuadiha3@gmail.com

${ }^{3}$ University of Management and Technology Lahore, Dept. of Mathematics, Pakistan.

abaid.math@gmail.com

${ }^{4}$ University of Education Lahore, Dept. of Mathematics, Pakistan.

rehman.mutee@yahoo.com

Received: February 2020 | Accepted: May 2020

\section{Abstract:}

Among topological descriptors topological indices are significant and they have a conspicuous role in chemistry. Dutch Windmill graph $D_{y}^{x}$ can be obtain by taking $x$ copies of cycle $C_{y}$ with a vertex in common. In this paper, we will compute some irregularity índices that are useful in quantitative structure activity relationship for Line Graph of Dutch Windmill graph.

Keywords: Dutch Windmill graph; Irregularity indices.

MSC (2020): 05C10, 05C12, 05C15, 05C22, 05C31.

\section{Cite this article as (IEEE citation style):}

M. A. Mohammed, S. Y. A. AL-Mayyahi, A. U. R. Virk, and H. M. U. Rehman, "Irregularity indices for line graph of Dutch windmill graph", Proyecciones (Antofagasta, On line), vol. 39, no. 4, pp. 903-918, Aug. 2020, doi: 10.22199/issn.0717-6279-2020-040056.

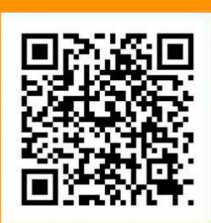

Article copyright: (C) 2020 Mohanad A. Mohammed, Suad Younus A. AL-Mayyahi, Abaid ur Rehman Virk and Hafiz Mutee ur Rehman. This is an open access article distributed under the terms of the Creative Commons License, which permits unrestricted use and distribution provided the original author and source are credited. 


\section{Introduction}

There are lot of curious real life issues that can be deciphered in the language of graph theory, where they are often found to have attractive solutions. Let $G=(V, E)$ be a simple connected graph, $V$ is the set of vertices and $E$ represents the number of edges present in graph. Degree of vertex means how many edges are attached with that vertex and is denoted by $d_{v}$ where $v \in V(G)$ and $e$ represents an edge $e=u v \in$ $E(G)$. Topological indices (TIs) help us to describe the structure of graph $[2,3,8,9,10,11,12,14,15,25]$. First ever TI was presented by Winer in 1947 [31], when he was trying to find out the boiling point of alkanes.

$$
W(G)=\sum_{(u, v) \subseteq V(G)} d_{G}(u, v)
$$

In 1975, Gutman gave a remarkable identity [32] about Zagreb indices. Hence, these two indices are among the oldest degree-based descriptors and their properties are extensively investigated. The mathematical formulae of these indices are:

$$
\begin{aligned}
& M_{1}(G)=\sum_{u v \in E(G)}\left(d_{u}+d_{v}\right), \\
& M_{2}(G)=\sum_{u v \in E(G)}\left(d_{u} \times d_{v}\right) .
\end{aligned}
$$

Historically, Zagreb indices are the very first degree based TIs, but these indices were used for completely different purpose, therefore the first genuine degree based TI is Randić index which was given in 1975 by Milan Randić [27] as:

$$
R(G)=\sum_{u v \in E(G)} \frac{1}{\sqrt{d_{u} \cdot d_{v}}} .
$$

An unexpected mathematical quality of Randić index is discovered recently, that tells us about the relation of this topological invariant with normalized Laplacian Matric [1,5,24]. The general Randić index [19] is defined as:

$$
G R I(G)=\sum_{u v \in E(G)}\left(d_{u} \cdot d_{v}\right)^{\alpha} .
$$

where $\alpha$ is an arbitrary real number. In Graph theory, the Line graph of a graph $G$ is represented by $L(G)$ that represents the adjacencies between the edges of G. The most important theorems about Line graphs is presented 
by Hassler Whitney [30] in (1932), he proved that with one exceptional case the structure of graph $G$ can be recovered completely from its Line graph.

A streamlined method of expressing the irregularity of graph is the irregularity index. Paul Erdös [6] first time study the irregularities of graph. The TI is known as Irregularity index, [28] if TI of graph is greater equal to zero and TI of graph is equal to zero if and only if graph is regular. The Irregularity indices are given below.

- $V A R(G)=\sum_{u \in V}\left(d_{u}-\frac{2 m}{n}\right)^{2}=\frac{M_{1}(G)}{n}-\left(\frac{2 m}{n}\right)^{2}$

- $A L(G)=\sum_{u v \in E(G)}\left|d_{u}-d_{v}\right|$

- $I R 1(G)=\sum_{u \in V}\left(d_{u}\right)^{3}-\frac{2 m}{n} \sum_{u \in V}\left(d_{u}\right)^{2}=F(G)-\frac{2 m}{n} M_{1}(G)$

- $I R 2(G)=\sqrt{\frac{\sum_{u v \in E(G)} d_{u} d_{v}}{m}}-\frac{2 m}{n}=\sqrt{\frac{M_{2}(G)}{m}}-\frac{2 m}{n}$

- $\operatorname{IRF}(G)=\sum_{u v \in E(G)}\left(d_{u}-d_{v}\right)^{2}=F(G)-2 M_{2}(G)$

- $\operatorname{IRFW}(G)=\frac{\operatorname{IRF}(G)}{M_{2}(G)}$

- $I R A(G)=\sum_{u v \in E(G)}\left(d_{u}^{-1 / 2}-d_{v}^{-1 / 2}\right)^{2}=n-2 R(G)$

- $\operatorname{IRB}(G)=\sum_{u v \in E(G)}\left(d_{u}^{1 / 2}-d_{v}^{1 / 2}\right)^{2}=M_{1}(G)-2 R R(G)$

- $I R C(G)=\frac{\sum_{u v \in E(G)} \sqrt{d_{u} d_{v}}}{m}-\frac{2 m}{n}=\frac{R R(G)}{m}-\frac{2 m}{n}$

- $\operatorname{IRDIF}(G)=\sum_{u v \in E(G)}\left|\frac{d_{u}}{d_{v}}-\frac{d_{v}}{d_{u}}\right|=\sum_{i<j} m_{i, j}\left(\frac{j}{i}-\frac{i}{j}\right)$

- $I R L(G)=\sum_{u v \in E(G)}\left|\ln d_{u}-\ln d_{v}\right|=\sum_{i<j} m_{i, j} \ln \left(\frac{j}{i}\right)$

- $\operatorname{IRLU}(G)=\sum_{u v \in E(G)} \frac{\left|d_{u}-d_{v}\right|}{\min \left(d_{u}, d_{v}\right)}=\sum_{i<j} m_{i, j} \ln \left(\frac{j-i}{i}\right)$

- $\operatorname{IRLF}(G)=\sum_{u v \in E(G)} \frac{\left|d_{u}-d_{v}\right|}{\sqrt{\left(d_{u} d_{v}\right)}}=\sum_{i<j} m_{i, j}\left(\frac{j-i}{\sqrt{i j}}\right)$ 
- $\operatorname{IRLA}(G)=2 \sum_{u v \in E(G)} \frac{\left|d_{u}-d_{v}\right|}{\left(d_{u}+d_{v}\right)}=2 \sum_{i<j} m_{i, j}\left(\frac{j-i}{i+j}\right)$

- $\operatorname{IRD} 1(G)=\sum_{u v \in E(G)} \ln 1+\left|d_{u}-d_{v}\right|=\sum_{i<j} m_{i, j} \ln (i+j-1)$

- $I R G A(G) \sum_{u v \in E(G)} \ln \left(\frac{d_{u}+d_{v}}{2 \sqrt{d_{u} d_{v}}}\right) \sum_{i<j} m_{i, j}\left(\frac{i+j}{2 \sqrt{i j}}\right)$

For more about TIs one can study $[7,13,16,17,18,20,21,22,23,26,29]$.

\section{Irregularity indices for Line Graph of Dutch Windmill Graph}

A graph $D_{y}^{x}$ with $x \geq 1$ and $y \geq 3$ is known as Dutch Windmill Graph [4]. $D_{y}^{x}$ can be obtain by taking $x$ copies of cycle $C_{y}$ with a vertex in common. Figure 1(a) shows the Dutch Windmill Graph $D_{y}^{x}$ with $x=4$ and $y=4$ and Figure 1(b) shows the line graph of Dutch Windmill Graph $D_{y}^{x}$ with $x=4$ and $y=4$. We can observe that the order of $L\left(D_{y}^{x}\right)$ is $x y$ and size of $L\left(D_{y}^{x}\right)$ is $2 x^{2}+x y-2 x$. We, now portioned the edge set according to their degrees. There are three types of edges present in line graph of Dutch Windmill Graph $E_{(2,2)}, E_{(2,2 x)}$ and $E_{(2 x, 2 x)}$. The frequencies of these edges are given in Table 1 .

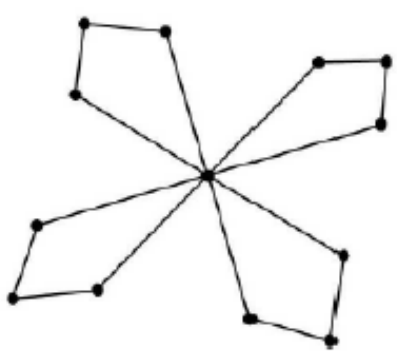

(a)

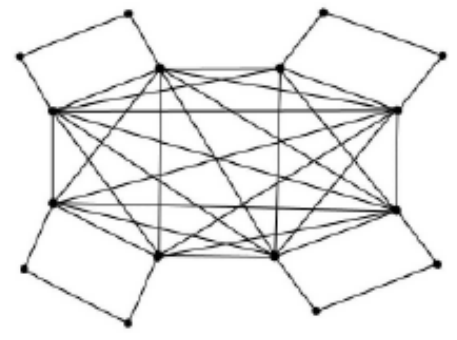

(b)

Figure 2.1: (a) $D_{4}^{4}, \quad$ (b) $L\left(D_{4}^{4}\right)$ 


\begin{tabular}{cc}
\hline$\left(d_{u}, d_{v}\right)$ & Frequency \\
\hline$(2,2)$ & $x(y-3)$ \\
$(2,2 x)$ & $2 x$ \\
$(2 x, 2 x)$ & $(2 x-1) x$ \\
\hline
\end{tabular}

Table 2.1: Partition of $E\left(D_{y}^{x}\right)$

Let $G$ be the Line Graph of Dutch Windmill Graph $D_{y}^{x}$ for $x \geq 1$ and $y \geq 3$, then we have

1. $\operatorname{VAR}(G)=\frac{4}{(y)^{2}}\left(2 x^{2} y-x^{2}-2 x y+2 x-1\right)$.

2. $A L(G)=4 x(1-x)$.

3. $\operatorname{IR} 1(G)=\frac{8 x}{y}\left(2 x^{3} y-2 x^{3}-2 x^{2} y+2 x^{2}-x y+2 x+y-2\right)$.

4. $\operatorname{IR} 2(G)=2\left(\sqrt{\frac{2 x^{3}-x^{2}+2 x+y-3}{x^{2}+x y-x}}-\frac{\left(x^{2}+x y-x\right)}{x y}\right)$.

5. $\operatorname{IRF}(G)=8 x\left(x^{2}-2 x+1\right)$.

\section{Proof.}

$$
\begin{gathered}
\operatorname{VAR}(G)=\sum_{u \in V}\left(d_{u}-\frac{2 m}{n}\right)^{2} \\
=\frac{M_{1}(G)}{n}-\left(\frac{2 m}{n}\right)^{2} \\
=\frac{4 x\left(2 x^{2}+y-2\right)}{x y}-\left(\frac{2 x(y-3)}{x y}\right)^{2} \\
=\frac{4}{(y)^{2}}\left(2 x^{2} y-x^{2}-2 x y+2 x-1\right) . \\
A L(G)=\sum_{u v \in E(G)}\left|d_{u}-d_{v}\right| \\
=|2-2|(x(y-3))+|2-3 x|(2 x)+|2 x-2 x|(x(2 x-1)) \\
=4 x(1-x) .
\end{gathered}
$$




$$
\begin{aligned}
& I R 1(G)=\sum_{u \in V} d_{u}^{3}-\frac{2 m}{n} \sum_{u \in V} d_{u}^{2} \\
& =F(G)-\left(\frac{2 m}{n}\right) M_{1}(G) \\
& =8 x(2 x+2 \sqrt{x}+x y-4)-\left(\frac{2\left(x^{2}+x y-x\right)}{x y}\right)\left(4 x\left(2 x^{2}+y-2\right)\right) \\
& =\frac{8 x}{y}\left(2 x^{3} y-2 x^{3}-2 x^{2} y+2 x^{2}-x y+2 x+y-2\right) \text {. } \\
& \operatorname{IR2}(G)=\sqrt{\frac{\sum_{u v \epsilon E(G)} d_{u} d_{v}}{m}}-\frac{2 m}{n} \\
& =\sqrt{\frac{M_{2}(G)}{m}}-\frac{2 m}{n} \\
& =\sqrt{\frac{4 x\left(2 x^{3}-x^{2}+2 x+y-3\right)}{\left(x^{2}+x y-x\right)}}-\frac{2\left(x^{2}+x y-x\right)}{x y} \\
& =2\left(\sqrt{\frac{2 x^{3}-x^{2}+2 x+y-3}{x^{2}+x y-x}}-\frac{\left(x^{2}+x y-x\right)}{x y}\right) \text {. } \\
& \operatorname{IRF}(G)=\sum_{u v \in E(G)}\left(d_{u}-d_{v}\right)^{2} \\
& =(12-2)^{2}(x y-3 x)+(2-2 x)^{2}(x y)+(2 x-2 x)^{2}(x(2 x-1)) \\
& =8 x\left(x^{2}-2 x+1\right) \text {. }
\end{aligned}
$$

Let $G$ be the Line Graph of Dutch Windmill Graph $D_{y}^{x}$ for $x \geq 1$ and $y \geq 3$, then we have

1. $\operatorname{IRF} W(G)=\frac{2\left(x^{2}-2 x+1\right)}{2 x^{3}-x^{2}+2 x+y-3}$.

2. $\operatorname{IRA}(G)=4-2 x-2 \sqrt{x}$.

3. $\operatorname{IRB}(G)=4 x(\sqrt{x}-1)^{2}$.

4. $\operatorname{IRC}(G)=\frac{2}{x y\left(x^{2}-x+x y\right)}\left(2 x^{5 / 2} y+2 x^{4} y-x^{4}-x^{3} y+x^{2} y^{2}+2 x^{3}-2 x^{2} y-\right.$ $\left.3 x^{2} y-x^{2}+2 x^{2} y-x y^{2}\right)$.

5. $\operatorname{IRDIF}(G)=2-2 x^{2}$. 


\section{Proof.}

$$
\begin{aligned}
& \operatorname{IRFW}(G)=\frac{\operatorname{IRF}(G)}{M_{2}(G)} \\
& =\frac{2\left(x^{2}-2 x+1\right)}{2 x^{3}-x^{2}+2 x+y-3} \text {. } \\
& \operatorname{IRA}(G)=\sum_{u v \in E(G)}\left(d_{u}^{-1 / 2}-d_{v}^{-1 / 2}\right)^{2} \\
& =n-2 R(G) \\
& =(x y)-2\left(\frac{1}{2}(2 x+2 \sqrt{x}+x y-4)\right) \\
& =4-2 x-2 \sqrt{x} \text {. } \\
& \begin{aligned}
\operatorname{IRB}(G)= & \sum_{u v \in E(G)}\left(d_{u}^{1 / 2}-d_{v}^{1 / 2}\right)^{2} \\
& =M_{1}(G)-2 R R(G) \\
= & (\sqrt{2}-\sqrt{2})^{2}(x(y-3))+(\sqrt{2}-\sqrt{2 x})^{2}(x y)+(\sqrt{2 x}-\sqrt{2 x})^{2}(x(2 x-1)) \\
= & 4 x(\sqrt{x}-1)^{2} .
\end{aligned} \\
& \operatorname{IRC}(G)=\frac{\sum_{u v \epsilon E(G)} \sqrt{d_{u} d_{v}}}{m}-\frac{2 m}{n} \\
& =\frac{R R(G)}{m}-\frac{2 m}{n} \\
& =\frac{\left(\sqrt{2 \times 2}(x y-3 x)+\sqrt{2 \times 2 x}(x y)+\sqrt{2 x \times 2 x}\left(2 x^{2}-x\right)\right)}{x^{2}-x+x y} \\
& -\frac{2\left(x^{2}-x+x y\right)}{x y} \\
& =\frac{2}{x y\left(x^{2}-x+x y\right)}\left(2 x^{5 / 2} y+2 x^{4} y-x^{4}-x^{3} y+x^{2} y^{2}+2 x^{3}\right. \\
& \left.-2 x^{2} y-3 x^{2} y-x^{2}+2 x^{2} y-x y^{2}\right) \text {. } \\
& \operatorname{IRDIF}(G)=\sum_{u v \in E(G)}\left|\frac{d_{u}}{d_{v}}-\frac{d_{v}}{d_{u}}\right| \\
& =\left|\frac{2}{2}-\frac{2}{2}\right|(x y-3 x)+\left|\frac{2}{2 x}-\frac{2 x}{2}\right|(x y)+\left|\frac{2 x}{2 x}-\frac{2 x}{2 x}\right|\left(2 x^{2}-x\right) \\
& =2-2 x^{2} \text {. }
\end{aligned}
$$


Let $G$ be the Line Graph of Dutch Windmill Graph $D_{y}^{x}$ for $x \geq 1$ and $y \geq 3$, then we have
1. $\operatorname{IRL}(G)=-2 \ln (x) x$.
2. $\operatorname{IRLF}(G)=(1-x) \sqrt{x} y$.
3. $\operatorname{IRLA}(G)=\frac{4 x(1-x)}{1+x}$.
4. $\operatorname{IRD} 1(G)=4 x(1-x)$.
5. $\operatorname{IRGA}(G)=2 \ln \left(\frac{(2+2 x)}{4 \sqrt{x}}\right)$.

\section{Proof.}

$$
\begin{aligned}
\operatorname{IRL}(G)= & \sum_{u v \in E(G)}\left|\ln d_{u}-\ln d_{v}\right| \\
= & |\ln 2-\ln 2|(x y-3 x)+|\ln 2-\ln (2 x)|(x y) \\
& +|\ln (2 x)-\ln (2 x)|\left(2 x^{2}-x\right) \\
= & -2 \ln (x) x . \\
\operatorname{IRLF}(G)= & \sum_{u v \in E(G)} \frac{\left|d_{u}-d_{v}\right|}{\sqrt{d_{u} \cdot d_{v}}} \\
= & \left(\frac{|2-2|}{\sqrt{2}}\right)(x y-3 x)+\left(\frac{|2-2 x|}{\sqrt{4 x}}\right)(x y) \\
& +\left(\frac{|2 x-2 x|}{\sqrt{4 x^{2}}}\right)\left(2 x^{2}-x\right) \\
= & (1-x) \sqrt{x} y . \\
I R L A(G)= & \sum_{u v \in E(G)} 2 \frac{\left|d_{u}-d_{v}\right|}{\left(d_{u}+d_{v}\right)} \\
= & 2\left(\frac{|2-2|}{2+2}\right)(x y-3)+2\left(\frac{|2-2 x|}{2+2 x}\right)(x y) \\
& +2\left(\frac{|2 x-2 x|}{2 x+2 x}\right)\left(2 x^{2}-x\right) \\
= & \frac{4 x(1-x)}{1+x} .
\end{aligned}
$$




$$
\begin{aligned}
\operatorname{IRD} 1(G)= & \sum_{u v \in E(G)} \ln \left\{1+\left|d_{u}-d_{v}\right|\right\} \\
= & \ln \{1+|2-2|\}(x y-3 x)+\ln \{1+|2-2 x|\}(x y) \\
& +\ln \{1+|2 x-2 x|\}\left(2 x^{2}-x\right) \\
= & 4 x(1-x) . \\
\operatorname{IRGA}(G)= & \sum_{u v \in E(G)} \ln \left(\frac{d_{u}+d_{v}}{2 \sqrt{d_{u} d_{v}}}\right) \\
= & \ln \left(\frac{2+2}{2 \sqrt{2 \times 2}}\right)(x y-3 x)+\ln \left(\frac{2+2 x}{2 \sqrt{2 \times 2 x}}\right)(x y) \\
& +\ln \left(\frac{2 x+2 x}{2 \sqrt{2 x \times 2 x}}\right)\left(2 x^{2}-x\right) \\
= & 2 \ln \left(\frac{(2+2 x)}{4 \sqrt{x}}\right) .
\end{aligned}
$$




\section{Graphical Representation}
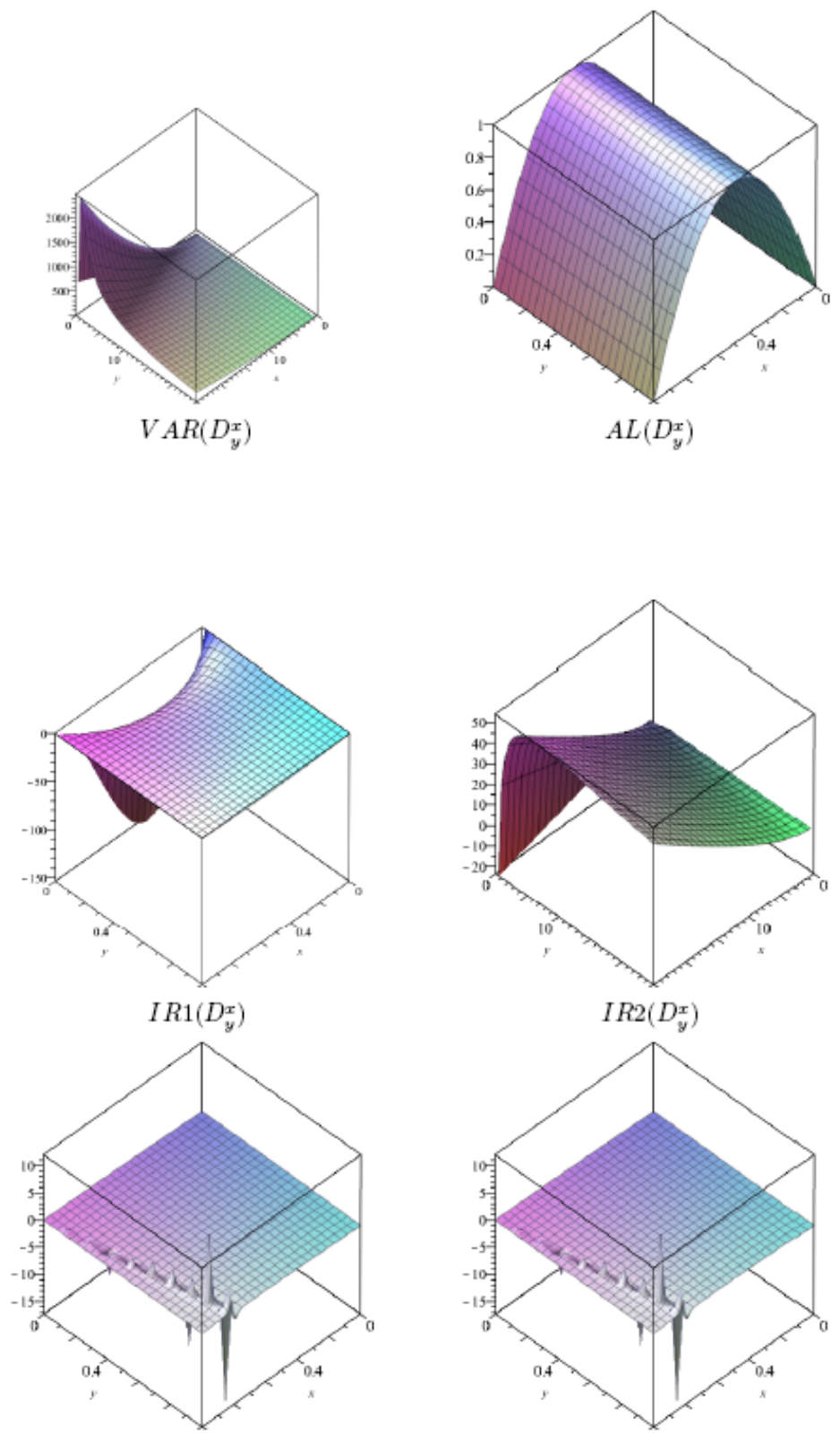

I R2 $\left(D_{y}^{x}\right)$

$\operatorname{IR} 2\left(D_{y}^{x}\right)$ 

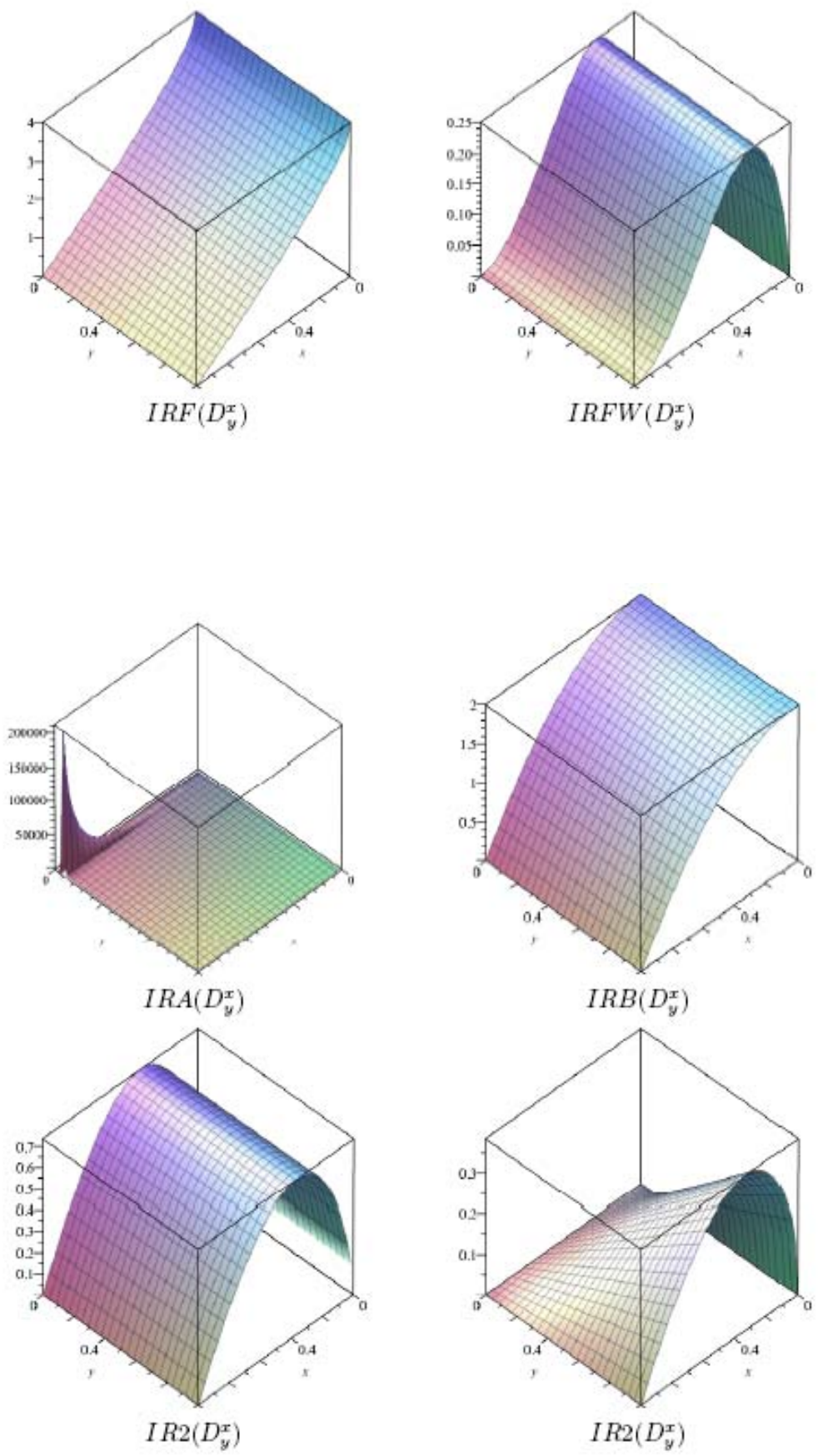

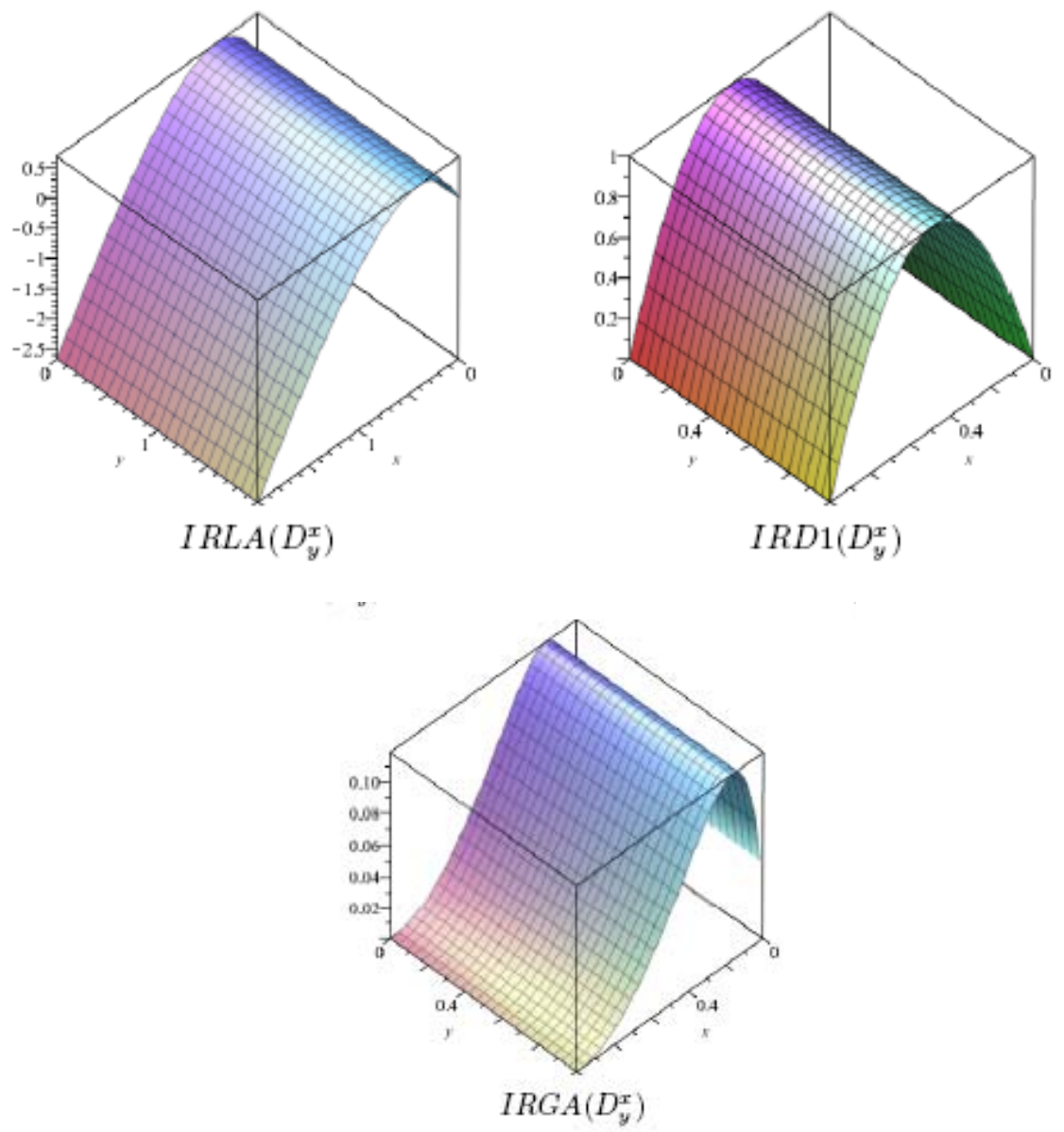

\section{Conclusions}

In this paper, we calculate sixteen irregularity indices for Line Graph of Dutch Windmill Graph $L\left(D_{y}^{x}\right)$. TIs are numeric quantities that help us to study different parameters of underlines structure. TIs are used for the development of quantitative structure-activity relationships (QSARs).

\section{Acknowledgements}

This study was supported by research funds from Dong-A University. 


\section{References}

[1] M. Ajmal, W. Nazeer, M. Munir, S. M. Kang, and C. Y. Jung, "The M-polynomials and topological indices of generalized prism network", International journal of mathematical analysis, vol. 11, pp. 293-303, 2017, doi: 10.12988/ijma.2017.7118

[2] D. Amić, D. Bešlo, B. Lučić, S. Nikolić, and N. Trinajstić, "The vertexconnectivity index revisited", Journal of chemical information and computer sciences, vol. 38, no. 5, pp. 819-822, Aug. 1998, doi: $10.1021 / \mathrm{ci} 980039 \mathrm{~b}$

[3] B. Bollobás, P. Erdös, "Graphs of extremal weights", Ars combinatoria, vol. 50, pp. 225-233, 1998.

[4] B. Chaluvaraju, H. S. Boregowda, and S. A. Diwakar, "Hyper-Zagreb indices and their polynomials of some special kinds of windmill graphs", International journal of advances in mathematics, vol. 4, pp. 21-32, 2017. [On line]. Available: https://bit.ly/2YSiyqg

[5] A. A. Dobrynin, R. Entringer, and I. Gutman, "Wiener Index of Trees: theory and applications", Acta applicandae mathematicae, vol. 66, no. 3, pp. 211-249, 2001, doi: 10.1023/A:1010767517079

[6] P. Erdöus, "Problems and results in combinatorial analysis and graph theory", Annals of discrete mathematics, vol. 38, pp. 81-92, 1988, doi: 10.1016/s0167-5060(08)70773-8

[7] O. Favaron, M. Mahéo, and J. F. Saclé, "Some eigenvalue properties in graphs (conjectures of Graffiti - II)", Discrete mathematics, vol. 111, no. 1-3, pp. 197-220, Feb. 1993, doi: 10.1016/0012-365x(93)90156-n

[8] W. Gao, J. L. G. Guirao, M. Abdel-Aty, and W. Xi, "An independent set degree condition for fractional critical deleted graphs", Discrete \& continuous dynamical systems - $S$, vol. 12 , no. 4-5, pp. 877-886, 2019, doi: $10.3934 /$ dcdss. 2019058

[9] W. Gao and M. R. Farahani, "Degree-based indices computation for special chemical molecular structures using edge dividing method", Applied mathematics and nonlinear sciences, vol. 1, no. 1, pp. 99-122, Jan. 2016, doi: 10.21042/amns.2016.1.00009 
[10] W. Gao and M. R. Farahani, and L. Shi, "The forgotten topological index of some drug structures", Acta medica mediterranea, vol. 32, no. 1, pp. 579-585, 2016. [On line]. Available: https://bit.ly/2AZShi3

[11] W. Gao, W. Wang, D. Dimitrov, and Y. Wang, "Nano properties analysis via fourth multiplicative ABC indicator calculating", Arabian journal of chemistry, vol. 11, no. 6, pp. 793-801, Sep. 2018, doi: 10.1016/j.arabjc.2017.12.024

[12] W. Gao, W. Wang, and M. R. Farahani, "Topological indices study of molecular structure in anticancer drugs", Journal of chemistry, vol. 2016, Art. ID-3216327, 2016, doi: 10.1155/2016/3216327

[13] W. Gao, Y. Wang, W. Wang, and L. Shi, "The first multiplication atombond connectivity index of molecular structures in drugs", Saudi pharmaceutical journal, vol. 25, no. 4, pp. 548-555, May 2017, doi: 10.1016/j.jsps.2017.04.021

[14] W. Gao, H. Wu, M. K. Siddiqui, and A. Q. Baig, "Study of biological networks using graph theory", Saudi journal of biological sciences, vol. 25, no. 6, pp. 1212-1219, Sep. 2018, doi: 10.1016/j.sjbs.2017.11.022

[15] M. Ghorbani, and M. Ghazi, "Computing some topological indices of triangular Benzenoid", Digest journal of nanomaterials and biostructures, vol. 5, no. 4, pp. 1107-1111, 2010. [On line]. Available: https://bit.ly/2YUDdu6

[16] C. K. Gupta, V. Lokesha, S. B. Shwetha, and P. S. Ranjini, "On the symmetric division deg index of graph", Southeast Asian Bulletin of Mathematics, vol. 40, no. 1, 2016. [On line]. Available: https://bit.ly/2BtCTu8

[17] I. Gutman, and K. C. Das, "The first Zagreb index 30 years after", MATCH communications in mathematical and in computer chemistry, vol. 50, no. 1, pp. 83-92, 2004. [On line]. Available: https://bit.ly/2YpODHe

[18] I. Gutman, B. Furtula, and C. Elphvick, "Three new/old vertex-degree based topological índices", MATCH communications in mathematical and in computer chemistry, vol. 72, no. 3, pp. 617-632, 2014. [On line]. Available: https://bit.ly/2Yq185B 
[19] I. Gutman, and O. E. Polansky, Mathematical concepts in organic chemistry. Berlin: Springer-Verlag, 2012.

[20] Y. Kwun, A. Virk, W. Nazeer, M. Rehman, and S. Kang, "On the multiplicative degree-based topological indices of silicon-carbon $\mathrm{Si}_{2} \mathrm{C}_{3}-\mathrm{I}[\mathrm{p}, \mathrm{q}]$ and $\mathrm{Si}_{2} \mathrm{C}_{3}$-II[p,q]", Symmetry, vol. 10, no. 8, Art ID. 320, Aug. 2018, doi: $10.3390 /$ sym 10080320

[21] X. Li and I. Gutman, Mathematical aspects of Randić-type molecular structure descriptors. Cacak: University. of Kragujevac, 2006.

[22] X. Li, and Y. Shi, "A survey on the Randić index", MATCH communications in mathematical and in computer chemistry, vol. 59, no. 1, pp. 127156, 2008. [On line]. Available: https://bit.ly/2YrVkbP

[23] A. Miličević, S. Nikolić, and N. Trinajstić, "On reformulated Zagreb indices", Molecular diversity, vol. 8, no. 4, pp. 393-399, 2004, doi: 10.1023/b:modi.0000047504.14261.2a

[24] M. Munir, W. Nazeer, Z. Shahzadi, and S. Kang, "Some invariants of circulant graphs", Symmetry, vol. 8, no. 11, p. 134, Nov. 2016, doi: $10.3390 /$ sym 8110134

[25] M. Naeem, M. K. Siddiqui, J. L. G. Guirao, and W. Gao, "New and modified eccentric indices of octagonal grid omn", Applied mathematics and nonlinear sciences, vol. 3, no. 1, pp. 209-228, 2018, doi: 10.21042/amns.2018.1.00016

[26] S. Nikolić, G. Kovačević, A. Miličević, and N. Trinajstic, "The Zagreb indices 30 years after", Croatica chemica acta, vol. 76, no. 2, pp. 113-124, 2003. [On line]. Available: https://bit.ly/3drifZ0

[27] M. Randić, "Characterization of molecular branching", Journal of the American Chemical Society, vol. 97, no. 23, pp. 6609-6615, Nov. 1975, doi: 10.1021/ja00856a001

[28] T. Réti, R. Sharafdini, A. Dregelyi-Kiss, and H. Haghbin, "Graph irregularity indices used as molecular descriptors in QSPR studies", MATCH communications in mathematical and in computer chemistry, vol. 79, no. 2, pp. 509-524, 2018. [On line]. Available: https://bit.ly/2YpajmT 
[29] D. Vukičević, D., and A. Graovac, "Valence connectivity versus Randić, Zagreb and modified Zagreb index: A linear algorithm to check discriminative properties of indices in acyclic molecular graphs", Croatica chemica acta, vol. 77, no. 3, pp. 501-508, 2004. [On line]. Available: https://bit.ly/2V9Jfpr

[30] H. Whitney, "A logical expansion in mathematics", Bulletin of the American Mathematical Society, vol. 38, no. 8, pp. 572-580, Aug. 1932, doi: 10.1090/s0002-9904-1932-05460-x

[31] H. Wiener, "Structural determination of paraffin boiling points", Journal of the American Chemical Society, vol. 69, no. 1, pp. 17-20, Jan. 1947, doi: $10.1021 / \mathrm{ja} 01193 \mathrm{a} 005$

[32] K. Yang, Z. Yu, Y. Luo, Y. Yang, L. Zhao, and X. Zhou, "Spatial and temporal variations in the relationship between lake water surface temperatures and water quality - A case study of Dianchi Lake", Science of the total environment, vol. 624, pp. 859-871, May 2018, doi: 10.1016/j.scitotenv.2017.12.119 